\title{
Kinerja Irigasi Tetes Tipe Emiter Aries pada Tanaman Pisang Cavendhis di PT Nusantara Tropical Farm
}

\section{Performances of Drip Irrigation with Aries Emitter Type on Cavendish Banana Crop di PT Nusantara Tropical Farm}

\section{Andre Velthuzend, Muhammad Idrus*, Didik Kuswadi, Suprapto, dan I Gde Darmaputra}

Politeknik Negeri Lampung

Email : idrusmuhammad62@polinela.ac.id

\begin{abstract}
This research was conducted in PT Nusantara Tropical Farm ( PT NTF) at Jepara, Margosakti, Labuhan Ratu, East Lampung District. The plants which were cultivated in PT NTF such as Cavendish banana, pineapple, crystal guava, and naga fruit. The irrigation being used to irrigated cavendish banana is drip irrigation method with Aries emitter type. Watering method of drip irrigation system that used for Cavendish banana is cross watering and block watering methods. The goals of this research were to determine the performance of drip irrigation line for Cavendish banana by using both kinds of watering method. The performance indicator of irrigation system included the conveyance efficiency, the uniformity coefficient, the length time irrigation, and the amount of fuel consumption for diesel machine of a pump. The result of this research showed that the value of the conveyance efficiency of drip irrigation with cross watering method was $90,2 \%$ and $80,0 \%$ for block watering method. The uniformity coefficient on cross watering method was $87,55 \%$ and $97,10 \%$ for block watering method. The amount of fuel consumption for 10,46 ha area with cross watering method was 29,49l and 40,52 l for 10,2 ha area with block watering method.
\end{abstract}

Keywords: block watering method, cross watering method, conveyance efficiency, fuel consumption and uniformity coefficient.

Disubmit: 11 November 2017, Diterima: 12 Desember 2017, Disetujui: 28 Desember 2017

\section{PENDAHULUAN}

Irigasi merupakan salah satu komponen terpenting dalam bercocok tanam, seiring dengan adanya perkembangan teknologi, irigasi pun menjadi lebih banyak ragamnya. Salah satu yang melatarbelakangi bertambah ragam irigasi adalah lebih banyak jenis tananaman yang dibudidayakan oleh petani. Pemberian air irigasi tidak dapat dilakukan secara asal-asalan karena setiap tanaman membutuhkan air yang dengan takaran yang berbeda-beda.

Kegiatan budidaya tanaman buah-buahan dapat dilakukan di lahan terbuka, namun dibutuhkan perhatian khusus dalam perawatannya. Dengan pemberian air sesuai dengan kebutuhkan dapat meningkatkan hasil produksi dari tanaman itu sendiri. Irigasi adalah sejumlah air yang pada umumnya diambil dari sungai atau bendung yang dialirkan melalui sistem jaringan irigasi untuk menjaga keseimbangan jumlah air di dalam tanah. Air irigasi dari sumber perlu dikelola dengan baik agar pemanfaatan air irigasi dapat maksimal.

Pemanfaatan air irigasi yang maksimal dapat dicapai diantaranya dengan menggunakan teknologi irigasi yang hemat air. Teknologi irigasi hemat air yang digunakan oleh PT Nusantara Tropical Farm yaitu irigasi 


\section{Jurnal Penelitian Pertanian Terapan}

tetes untuk mengairi pertanaman pisang Cavendish. Tanaman pisang Cavendish dapat tumbuh dan berkembang dengan baik pada daerah yang memiliki iklim tropis basah, lembab dan panas. Walaupun demikian tanaman pisang masih dapat tumbuh di daerah subtropis. Selain itu pada kondisi tanpa air, pisang masih tetap tumbuh karena air disuplai dari batangnya yang berair tetapi produksinya sangat sedikit. Curah hujan optimal adalah 1,520-3,800 mm/tahun dengan 2 bulan kering (Robinson \& Sauco, 2010). Pertanaman pisang Cavendish PT Nusantara Tropical Farm terletak di Jepara, Desa Margo Sakti, Kecamatan Labuhan Ratu, Kabupaten Lampung Timur yang sering mengalami bulan-bulan kering selama $2-4$ bulan sehingga perusahaan melakukan penyiraman dengan menggunakan irigasi tetes pada pertanaman pisang pada bulanbulan kering tersebut agar pisang Cavendish tetap dapat berproduksi secara maksimal.

Pemakaian irigasi tetes telah meluas pada banyak komoditas khususnya tanaman sayuran dan tanaman buah-buahan untuk memperbaiki efisiensi penggunaan air dan menghemat persediaan air (Jayapiratha et al., 2010 dan Shiri-e-Janagrad et al., 2009). Irigasi tetes merupakan satu tipe irigasi mikro yang mempunyai potensi menghemat air dan nurisi dengan cara meneteskan air secara lambat ke daerah perakaran tanaman baik di atas permukaan tanah maupun di bawah permukaan tanah (Smeal, 2007). Potensi efisiensi pemakaian air beberapa metode irigasi yang dirancang dengan baik disertai dengan pengelolaan irigasi yang baik pula yaitu sistem irigasi permukaan $45-80 \%$, sistem irigasi sprinkler $65-90 \%$, dan sistem irigasi tetes $80-95 \%$ (Irmak et al., 2011).

Ada dua metode penyiraman irigasi tetes yang biasa dilakukan oleh PT Nusantara Tropical Farm, yaitu metode penyiraman silang dan penyiraman blok pada pertanaman pisang Cavendish Plot 8b seluas 28,45 ha. Metode penyiraman silang yaitu cara penyiraman pada plot-plot pertanaman pisang yang saling berjauhan dalam 1 sift penyiraman, sedangkan metode penyiraman blok yaitu cara penyiraman pada plot-plot pertanaman pisang yang saling berdekatan dalam 1 sift penyiraman. Ketidaktepatan dalam memilih metode penyiraman dapat mengakibatkan terjadinya ketidak seragaman debit penyiraman, penambahan jam siram pada blok tanam yang terjauh, penambahan volume bahan bakar karena terjadi penambahan waktu siram. Kondisi tersebut memerlukan evaluasi penerapan kedua metode penyiraman tersebut untuk menentukan metode penyiraman jaringan irigasi tetes yang efisien dan efektif, agar dapat menghemat penggunaan air, kebutuhan bahan bakar mesin, dan mempermudah tenaga kerja dalam proses penyiraman dan pemeliharaan jaringan irigasi.

Agar pemanfaatan air irigasi dengan menggunakan irigasi tetes maka penyiraman harus secara merata pada seluruh areal pertanaman yang ditandai dengan dengan variasi debit yang rendah dan nilai koefisien keseragaman (efisiensi distribusi air) yang tinggi. Peacock \& Handley (2017) mengemukakan bahwa koefisien keseragaman air harus menjadi pertimbangan dalam pengelolaan sistem irigasi. Nilai koefisien keseragaman air yang rendah menunjukkan terjadi banyak emiter yang tersumbat dan masalah pada pengatur tekanan dalam jaringan irigasi tetes. Koefisiesn keseragaman air irigasi merupakan indikator penting dalam evaluasi kinerja suatu sistem irigasi dan dipengaruhi oleh topografi lahan, perancangan hidrolika sistem irigasi seperti halnya penyumbatan sebagian atau keseluruhan emiter (Zhu et al., 2010).

Valiahary et al., (2014) mengemukakan bahwa evaluasi nilai koefisien keseragaman air irigasi tetes didasarkan pada nilai koefisien keseragaman yang telah dikemukakan oleh Meriam dan Keller pada Tabel 1 berikut.

Tabel 1. Kelasifikasi nilai koefisien keseragaman irigasi

\begin{tabular}{cc}
\hline Nilai Koefisien Keseragaman $(\mathrm{EU})(\%)$ & Kelas \\
\hline$>90 \%$ & Sangat baik \\
$80-90$ & Baik \\
$70-80$ & Cukup/sedang \\
$<70$ & Buruk \\
\hline
\end{tabular}


Velthuzend, dkk : Kinerja Irigasi Tetes Tipe Emiter Aries pada Tanaman Pisang Cavendhis di PT Nusantara Tropical...

Penelitian bertujuan untuk mengukur kinerja jaringan irigasi tetes yang meliputi (1) Menentukan nilai efisiensi penyaluran kedua metode sistem penyiraman, (2) Menentukan nilai keseragaman siraman air pada 2 metode sistem penyiraman, (3) Menentukan lama waktu penyiraman kedua metode sistem penyiraman, dan (4) Menentukan jumlah pemakaian bahan bakar engine kedua metode sistem penyiraman.

\section{METODE PENELITIAN}

Penelitian dilaksanakan pada Plot tanam pisang Cavendhis 8b di PT Nusantara Tropical Farm (NTF) Jepara Desa Margo Sakti, Kecamatan Labuhan Ratu, Kabupaten Lampung Timur, Lampung. Data yang diperlukan dalam penelitian adalah data sekunder berupa data kebutuhan air tanaman pisang. Alat yang digunakan dalam penelitian yaitu jaringan irigasi tetes tipe selang drip Aries, stopwatch, gelas ukur, tachometer, dan pressure gauge. Pengukuran debit pompa dilakukan dengan pengamatan pada alat pengukur debit yang terpasang pada pipa outlet pompa. Hal ini dilakukan agar debit outlet pompa dapat diketahui. Pengukuran rpm atau putaran pompa dilakukan dengan meletakan sensor tachometer pada mesin pompa. Dan untuk pengukuran tekanan pompa dengan mengamati pressure gauge yang telah terpasang pada pipa outlet pompa.

Pengukuran debit emiter dilakukan dengan metode volumetri pada blok 8b04. Waktu pelaksanaan pengukuran pada saat penyiraman berlangsung, dengan cara memasang gelas ukur pada 18 titik penyiraman. Pada selang flatnet terdapat conector yang menghubungkan selang flatnet dan selang aries. Titik pengukuran dilakukan pada bagian pangkal, tengah dan ujung selang flatnet, lalu gelas ukur dipasang pada selang emiter yang terhubung pada selang flatnet 3" dan 2", masing 3 gelas ukur dipasang pada selang aries pada bagian pangkal, tengah, dan ujung. Maka pada selang flatnet ukuran 3"' terdapat 9 titik pengukuran dan pada selang flatnet ukuran 2" terdapat 9 titik. Tentukan lama waktu pengukuran debit dan ukur volume air yang tertampung dalam gelas ukur selama pengukuran. Debit emitter dihitung dengan cara membagi volume aliran yang tertampung (liter) dengan lama waktu pengukuran (detik).

Koefesien keseragaman. Keseragaman aplikasi air merupakan salah satu faktor penentu efisiensi irigasi yang dihitung dengan persamaan koefisien keseragaman air irigasi (CU/Coefficient Uniformity) dengan menggunakan persamaan Christiansen (Irma, Odhiambo, Kranz, Eisenhauer, 2011). Koefisien keseragaman irigasi dihitung dengan cara satu dikurangi dengan hasil pembagian antara jumlah deviasi absolut volume setiap hasil pengukuran terhadap rata-rata volume hasil pengukuran $(\mathrm{ml})$ dengan total volume hasil pengukuran (ml) kemudian dikalikan $100 \%$.

Efisiensi penyaluran. Perhitungan pemberian air irigasi dilakukan untuk mengevaluasi kehilangan seberapa besar persentase air tersampaikan ke tanaman dalam saluran irigasi. Hal ini merupakan tahapan selanjutnya yang dilakukan setelah pengukuran debit air irigasi. Efisiensi penyaluran air irigasi (\%) dihitung dengan cara membagi air yang disalurkan ke areal pertanaman $\left(\mathrm{m}^{3}\right)$ dengan air yang diambil dari sumber air $\left(\mathrm{m}^{3}\right)$ kemudian dikalikan $100 \%$.

Tabel 2. Kebutuhan air tanaman pisang Cavendish (ETc)

\begin{tabular}{lc}
\hline Umur tanaman & Kebutuhan air tanaman(mm/hari) \\
\hline $0-2$ bulan & 3,00 \\
3-5 bulan & 5,00 \\
6-12 bulan & 7,00 \\
\hline
\end{tabular}

Sumber : Tim Riset PT. Nusantara Tropical Farm

Lama waktu penyiraman. Lama waktu penyiraman dapat ditentukan dengan menggunakan persamaan (FAO, 1986) dan (Shukla et al., 2014). Lama waktu penyiraman (jam) dihitung dengan cara mengalikan kebutuhan air irigasi $(\mathrm{mm})$ dengan luas pertanaman (ha) dibagi dengan debit air irigasi (1/dt) kemudian dikalikan dengan 2,78. Kebutuhan air irigasi $(\mathrm{mm})$ diperoleh dari hasil perkalian antara evapotranspirasi 


\section{Jurnal Penelitian Pertanian Terapan}

tanaman (mm/hari) dengan selang waktu irigasi (hari) kemudian dibagi dengan efisiensi irigasi (desimal). Kebutuhan air tanaman pisang Cavendish (ETc) dapat dilihat pada Tabel 2.

Jumlah Pemakaian bahan bakar. Jumlah bahan bakar yang digunakan dalam satu kali proses penyiraman merupakan salah satu hal yang perlu dikaji. Hal ini dapat dihitung dengan mengetahui lama waktu yang diperlukan untuk melakukan 1 kali penyiraman sesuai kebutuhan air yang diperlukan untuk seluruh areal tanaman Cavendish baik dengan menggunakan metode peyiraman silang maupun dengan metode penyiraman blok. Jumlah pemakaian BBm solar mesin diesel pompa adalah perkalian antara lama waktu penyiraman dengan jumlah pemakaian BBM solar mesin diesel pompa per jam.

\section{HASIL DAN PEMBAHASAN}

Koefisien Keseragaman Air. Hasil pengukuran debit emiter irigasi tetes pada pertanaman pisan Cavendish di PT Nusantara Tropical Farm pada saat pemberian air irigasi dengan metode penyiraman silang dan metode penyiraman blok dapat dilihat pada Tabel 3. Debit maksimum, debit minimum, dan debit rata-rata emiter irigasi tetes pada metode penyiraman silang berturut-turut 2,80 1/jam, 1,98 1/jam, dan 2,40 1/jam, sedangkan dengan mentode penyiraman blok berturut-turut 2,0 1/jam, 1,8 1/jam, dan 1,97 1/jam (Tabel 3). Lebih rendahnya debit pada metode penyiraman blok dapat disebabkan oleh lebih banyaknya debit air yang hilang melalui sambungan-sambungan antarpipa dan koneksi antara jaringan lateral dengan jaringan pipa sub utama.

Tabel 3. Rata-rata debit emiter hasil pengukuran selama pemberian air irigasi pada pertanaman pisang Cavendish

\begin{tabular}{|c|c|c|c|c|}
\hline \multirow{2}{*}{ No. sample emiter } & \multicolumn{2}{|c|}{ Metode Penyiraman Silang } & \multicolumn{2}{|c|}{ Metode Penyiraman Blok } \\
\hline & Debit (1/jam) & $|\mathrm{xi}-\bar{x}|$ & Debit (1/jam) & $\mathrm{xi}-\overline{\boldsymbol{x}}$ \\
\hline 1 & 2,16 & 0,24 & 2 & 0,03 \\
\hline 2 & 2,16 & 0,24 & 2 & 0,03 \\
\hline 3 & 2,16 & 0,24 & 1,8 & 0,17 \\
\hline 4 & 1,98 & 0,42 & 2 & 0,03 \\
\hline 5 & 1,98 & 0,42 & 2 & 0.03 \\
\hline 6 & 2,16 & 0,24 & 2 & 0,03 \\
\hline 7 & 2,16 & 0,24 & 1,8 & 0,17 \\
\hline 8 & 2,00 & 0,40 & 2 & 0,03 \\
\hline 9 & 2,16 & 0,24 & 2 & 0,03 \\
\hline 10 & 2,80 & 0,40 & 2 & 0,03 \\
\hline 11 & 2,70 & 0,30 & 2 & 0,03 \\
\hline 12 & 2,80 & 0,40 & 2 & 0,03 \\
\hline 13 & 2,80 & 0,40 & 2 & 0,03 \\
\hline 14 & 2,60 & 0,20 & 2 & 0,03 \\
\hline 15 & 2,60 & 0,20 & 2 & 0,03 \\
\hline 16 & 2,80 & 0,40 & 2 & 0,03 \\
\hline 17 & 2,60 & 0,20 & 2 & 0,03 \\
\hline 18 & 2,60 & 0,20 & 1,8 & 0,17 \\
\hline Jumlah & 43,22 & 5,38 & 35,40 & 1,00 \\
\hline Rata-rata & 2,40 & & 1,97 & \\
\hline Cu (\%) & & & & \\
\hline
\end{tabular}

Koefisien keseragaman irigasi tetes pada metode penyiraman silang sebesar 87,55\% jauh lebih rendah dibandingkan dengan metode penyiraman blok sebesar 97,18\%. Hal ini dapat disebabkan oleh tingginya kehilangan tekanan pada metode penyiraman silang akibat gesekan sepanjang pipa uatama dan pipa sub utama sehingga terjadi variasi tekanan yang lebih tinggi di hulu jaringan lateral pada metode penyiraman silang. Indikator kehilangan tekanan yang tinggi pada metode penyiraman silang yaitu tekanan aliran hanya sebesar 2,7 bar sedangkan pada metode penyiraman blok tekanan aliran sebesar 3,5 bar pada rotasi putaran per menit (rpm) pompa yang sama. Peacock \& Handley (2017) mengemukakan nilai koefisien keseragaman yang tinggi ditandai oleh variasi debit aliran yang kecil antar emiter. Selanjutnya, dikatakan bahwa penyumbatan emiter 
dan distribusi tekanan yang yang tidak merata merupakan faktor utama penyebab inefisiensi atau koefisien keseragaman air yang rendah.

Berdasarkan klasifikasi nilai koefisien keseragaman air pada Tabel 3 maka nilai koefisien keseragaman air irigasi tetes dengan metode penyiraman silang sebesar $87,55 \%$ tergolong baik dan dengan metode penyiraman blok sebesar 97,18 tergolong sangat baik. Hal ini menunjukkan bahwa kondisi lubang emiter jaringan irigasi tetes PT Nusantara Tropical Farm masih bersih dan distribusi tekanan pada jaringan irigasi masih merata.

Tabel 4. Data jaringan irigasi dan debit untuk masing-masing metode penyiraman.

\begin{tabular}{|c|c|c|c|}
\hline Parameter & Satuan & Metode Penyiraman Silang & Metode Penyiraman Blok \\
\hline Luas, A & ha & 10,46 & 10,2 \\
\hline Rpm & Rpm & 1600 & 1600 \\
\hline Tekanan aliran & bar & 2,7 & 3,5 \\
\hline Panjang lateral, 1 & $\mathrm{~m}$ & 101 & 101 \\
\hline Jarak antarbaris & $\mathrm{m}$ & 3 & 3 \\
\hline Jumlah baris, $\mathrm{x}$ & baris & 32 & 32 \\
\hline Jarak lubang emiter, $\mathrm{z}$ & $\mathrm{m}$ & 0,75 & 0,75 \\
\hline Jumlah emiter, np & buah & 45.075 & 43.955 \\
\hline Debit aktual rata-rata per emiter, Qa & $\mathrm{m}^{3} / \mathrm{jam}$ & 0,0024 & 0,00197 \\
\hline Volume air sampai farm, Wf & $\mathrm{m}^{3}$ & 108,32 & 86,4 \\
\hline Volume pemompaan air dari sumber, Wr & $\mathrm{m}^{3}$ & 120 & 108 \\
\hline Efisiensi penyaluran, Ec & $\%$ & 90,2 & 80 \\
\hline
\end{tabular}

Efisiensi penyaluran air irigasi. Metode penyiraman mempengaruhi volume pemompaan air dari sumber meskipun nilai rpm pompa disamakan (Tabel 4). Volume pemompaan air dari sumber dengan metode penyiraman silang sebesar $120 \mathrm{~m}^{3}$ lebih besar dibandingkan dengan metode penyiraman blok yang hanya 108 $\mathrm{m}^{3}$. Hal ini dapat disebabkan oleh volume ruang jaringan pipa pada saat penyiraman dengan metode penyiraman silang lebih besar dibandingkan dengan metode penyiraman blok sehingga efek tekanan aliran balik lebih rendah dibandingkan dengan metode penyiraman blok. Efek tekanan aliran balik akibat volume runag yang kecil dapat menurunkan kapasitas pengaliran pompa.

Tabel 5. Luas siram, kebutuhan air pisang cavendish, lama penyiraman dan jumlah pemakaian bahan bakar solar

\begin{tabular}{lccc}
\hline \multicolumn{1}{c}{ Parameter } & Satuan & Metode Penyiraman Silang & Metode Penyiraman Blok \\
\hline Luas siram, A & ha & 10,46 & 10,2 \\
Jumlah emiter, ne & buah & 45.075 & 43.955 \\
Debit aktual rata-rata per emiter, Qe & $1 /$ jam & 2,40 & 1,97 \\
Total Qe & $(1 /$ dt) & 30,05 & 24,05 \\
Kebutuhan air tanaman, ETc & mm/hari & 5 & 5 \\
Selang waktu irigasi, Ii & hari & 1 & 1 \\
Efisiensi irigasi, Eo & $\%$ & 90,2 & 80,0 \\
Kebutuhan air irigasi, IR & $\mathrm{mm}$ & 5,54 & 6,25 \\
Lama waktu penyiraman, Ti & jam/hari & 5,36 & 7,37 \\
Pemakaian solar & $1 /$ jam & 5,5 & 5,5 \\
Total jumlah pemakaian solar & 1 & 29,49 & 40,52 \\
Jumlah pemakaian solar per hektar & $1 / h a$ & 2,82 & 3,97 \\
\hline
\end{tabular}

Efisiensi penyaluran air irigasi dengan metode penyiraman silang sebesar 90,2\% jauh lebih tinggi daripada metode penyiraman blok yang hanya $80,0 \%$ (Tabel 4). Hal ini terjadi karena pada metode penyiraman blok lebih banyak terjadi kehilang air sebesar 20\%, sedangkan dengan metode penyiraman silang hanya 9,8\%. Tingginya kehilangan air irigasi pada metode penyiraman blok dapat disebabkan oleh tingginya tekanan aliran (Tabel 4) saat penyiraman yang dapat meningkatkan kebocoran-kebocoran melalui celah-celah sambungan 


\section{Jurnal Penelitian Pertanian Terapan}

jaringan pipa dan pada koneksi setiap emiter. Jarak tanam, jumlah tanaman pisang Cavendish, kebutuhan air tanaman pisang Cavebdish dapat dilihat pada Tabel 5.

Lama waktu penyiraman aktual sistem irigasi tetes pada pertanaman pisang Cavendish blok $8 \mathrm{~b}$ seluas 10,46 ha pada metode penyiraman silang yaitu 5,36 jam, sedangkan pada metode penyiraman blok selama 7,37 jam untuk luas lahan 10,2 ha (Tabel 5). Lama penyiraman sangat tergantung pada besarnya debit rata-rata emiter untuk memenuhi kebutuhan air pisang Cavendish. Jumlah pemakaian solar pada metode penyiraman silang pada lahan pertanaman pisang Cavendih seluas 10,46 ha sebanyak 29,49 1 (2,82 1/ha) lebih rendah dibandingkan metode penyiraman blok seluas 10,2 ha sebesar 40,52 1 (3,97 1/ha). Jumlah pemakaian solar tergantung pada lamanya penyiraman tanaman pisang Cavendish.

\section{KESIMPULAN DAN SARAN}

Metode penyiraman berpengaruh terhadap kinerja irigasi tetes pada pertanaman pisang Cavendish di PT Nusantara Tropical Farm. Metode penyiraman silang irigasi tetes pada pertanaman pisang Cavendish di PT Nusantara Tropical Farm lebih efisien pemakaian air dan bahan bakar solar mesin diesel pompa dibandingkan dengan metode penyiraman blok. Penelitian lanjutan perlu dilakukan untuk melihat pengaruh metode penyiraman irigasi tetes tanaman pisang Cavendish terhadap produksi dan produktivitas air irigasi.

\section{DAFTAR PUSTAKA}

FAO 1986. Irrigation Water Management Training manual no. 5: Irrigation Methods. Tersedia di http://www.fao.org/docrep/s8684e/s8684e00.htm\#Contents [Accessed 8 Oktober 2017].

Irmak, S., Odhiambo, L.O., Kranz, W.L. \& Eisenhauer, D.E. 2011. Irrigation Efficiency and Uniformity, and Crop Water Use Efficiency. Biological Systems Engineering: Papers and Publications, 451.

Jayapiratha, V., Thushyanthy, M. \& Sivakumar, S. 2010. Performance Evaluation of Okra (Abelmoshus esculentus) under Drip Irrigation System. Asian Journal of Agricultural Research, 4(3): 139-147.

Peacock, B. \& Handley, D. 2017. Drip Irrigation Must Apply Water Uniformly to be Efficient. Tersedia di http://cetulare.ucdavis.edu/files/82036.pdf [Accessed 20 September 2017].

Robinson, J.H. \& Sauco, V.G. 2010. Banana and Plantains. 2nd ed. USA: CABI North America Office.

Shiri-e-Janagrad, M., Tobeh, A., Hokmalipour, S., Jamaati-e-Somarin, S., Abbasi, A. \& Shahbazi, K. 2009. Potato (Solanum tuberosum L.) response to drip irrigation regimes and plant arrangements during growth periods. Asian Journal of Plant Sciences, 8(6): 390-399.

Shukla, S., Knowles, J.M. \& Shrestha, N.K. 2014. How to determine run time and irrigation cycles for drip irrigation: tomato and pepper examples. Cooperative Extension Service, IFAS, University of Florida, AE500, 1-5. Tersedia di http://edis.ifas.ufl.edu/ae500.

Smeal, D. 2007. Drip Irrigation for Small Plots (a low-tech, low-cost, gravity system). Albuquerque, NM: New Mexico Organic Farming Conference.

Valiahary, S., Sadraddini, A.A., Nazemi, A.H. \& Majnooni-Heris, A. 2014. Field Evaluation of Emission Uniformity for Trickle Irrigation Systems(Case Study: Sattarkhan Irrigation Network). Agriculture Science Developments, 3(6).

Zhu, D.L., Wu, P.T., Merkley, G.P. \& Jin, J. 2010. Drip irrigation lateral design procedure based on emission uniformity and field microtopography. Irrigation And Drainage, 59(5): 535-549. 